\title{
O Canto dos Ladrões: tradução e notas d'As Metamorfoses 4.8-22 de Apuleio
}

\author{
Emerson Cerdas*
}

\section{Introdução}

Apresentamos, a seguir, a tradução de um episódio do romance de Apuleio, $A s$ Metamorfoses, também conhecido como O Asno de Ouro. Intitulamos este episódio de "O canto dos ladrões" para refletir o aspecto literário que nos chama mais atenção nele: o caráter paródico com o canto épico. O personagem principal Lúcio, já transformado em asno, é levado por ladrões da casa de seu anfitrião Milão de Hípata para o esconderijo do grupo. Lá, em meio à comida, à bebida e à conversação dos bandidos, um deles passa a narrar a história do assalto que uma parte do grupo fez e Lúcio, em sua forma de asno, pode saciar a sua curiosidade (ingenita curiositas), já que, como próprio narrador afirma em IX.13, com este novo aspecto, as pessoas se aproximavam dele falando e agindo livremente (et agunt et loquuntur).

$\mathrm{O}$ romance antigo é o sucessor da épica como uma longa narrativa ficcional mista (BRANDÃO, 2005, p.218), e o débito com este tipo de poesia é parte essencial da linguagem do romance antigo, com seus jogos de aproximação e distanciamento de temas e técnicas narrativas, e, portanto, é natural que a épica seja recorrentemente referenciada por esse discurso parodístico. Conforme Harrison ${ }^{1}$ comenta (2003, p.515), há muitos elementos de imitação da épica na obra de Apuleio, especialmente na semelhante postura de Lúcio, narrador de sua própria aventura, com a de Odisseu, que nos cantos IX-XII da Odisseia substitui a voz do aedo e canta suas aventuras durante os dez anos em que esteve perdido no mar.

Para Bakhtin, as Metamorfoses de Apuleio, como o Satíricon de Petrônio, são sátiras menipeias desenvolvidas à maneira romanesca. Essa natureza do texto de Apuleio fica evidente ao considerarmos o elevado caráter cômico e paródico do romance, jogando o tempo todo com a tradição literária para criar um discurso ambivalente que reverbera não o mundo elevado da épica, mas o mundo rebaixado da sátira menipeia. A paródia é um elemento essencial à sátira menipeia e a tudo quanto seja gênero carnavalizado, pois na paródia "[...] o autor fala a linguagem do outro, porém, diferentemente da estilização, reveste essa linguagem de orientação significativa diametralmente oposta à orientação do outro" (BAKHTIN, 1981, p.168), ou seja, no discurso parodístico, usam-se as mesmas palavras do texto parodiado para significarem coisas diferentes ou até mesmo opostas. Conforme Odil (1993, p.49),

A paródia carnavalesca é a paródia dialógica e não uma simples "negação pobre do parodiado". Ela é ambivalente, joga com diferentes imagens que se parodiam umas às outras de diversas maneiras e sob diferentes pontos de vista. Para Bakhtin, é esta a paródia carnavalesca da Antiguidade, do Renascimento e dos duplos parodiadores em Dostoiévski. Ela não é

\footnotetext{
* Doutorado em Estudos Literários pela Universidade Estadual Paulista Júlio de Mesquita Filho (2016).

${ }^{1}$ As análises de Harrison a respeito da imitação de Apuleio com as épicas antigas podem ser vistas, por exemplo, nos artigos "Some Odyssean Scenes in Apuleius' Metamorphoses" (1990) e "From Epic to Novel: Apuleius' Metamorphoses and Vergil's Aeneid" (1997), "Apuleius and Homer: Some Traces of the Iliad in the Metamorphoses" (2009).
} 
simplesmente negação; ao contrário, o que é negado o é para superar-se: a morte de um significa o renovar-se em direção a um outro.

No episódio em questão, a paródia se dá pela ambivalência do discurso do ladrão-narrador que se utiliza de um estilo elevado para engrandecer as ações baixas praticadas por ele e seus companheiros. O episódio se inicia como uma resposta do ladrão ao líder do bando acerca dos motivos de ele ter voltado do assalto com tão poucas coisas, sendo que fora invadir as casas mais pobres. O narrador, então, tenta justificar o fracasso do grupo com o uso de um discurso elevado que, segundo Adkins (2014, pp. 47-49), estrutura-se como um discurso jurídico de defesa e apropria-se de uma linguagem épica e militar para apresentar-se como um grupo militarmente organizado. A partir disso, ele narra três tentativas de assalto que culminam com a morte de três dos bandidos, Lâmaco, Alcimo e Trasileão. Esses ladrões são caracterizados como homens nobres, de grande valor moral, corajosos, mas mostram-se, no decorrer da ação, incapazes de derrotar velhos e velhas, e são constantemente enganados por eles. Ao mesmo tempo, as ações praticadas pelos ladrões, descritas como arrojadas e cheias de perspicácia, muitas vezes não passam de ações simples, como enfiar a mão pela porta e puxar o trinco da fechadura.

Por isso, nossa tradução buscou explicitar esses elementos de paródia do discurso épico no episódio "O canto dos ladrões" das Metamorfoses de Apuleio. Tendo esse horizonte em mente, buscamos criar em vernáculo elementos que nos parecem essenciais no texto original, em especial essa bivocalidade do discurso do narrador que, tentando engrandecer a sua história com um discurso empolado, acaba criando o riso justamente pelo descompasso entre discurso elevado e ação baixa. Nesse sentido, aproveitamos algumas fórmulas tradicionais, já consagradas em traduções dos épicos em língua portuguesa, em nossa própria tradução, como em Met. IV.11, em que usamos a expressão "imo peito" para traduzir per medium pectus, ou em Met. IV.18, em que usamos o epíteto iliádico de Aquiles, "pés velozes", para traduzir concito gradu.

Outro aspecto interessante do texto de Apuleio que buscamos manter é o empolamento do discurso do ladrão, que muitas vezes se torna confuso, com construções sintáticas complexas. A tradução de 1963 de Ruth Guimarães (APULEIO, 1963), por exemplo, busca clarear essas dificuldades textuais, organizando em português as orações subordinadas de modo a tornar o conteúdo mais apetecível para o leitor. Acreditamos, no entanto, que isso acaba por infringir o próprio objetivo do texto de Apuleio, que faz uso desses entrechos complicados, justamente, nas cenas de maior ação e movimentação. Em Met. IV.12, por exemplo, o intricado jogo sintático criado, nos parece, visa a recriar pelo acúmulo de subordinadas a própria confusão da cena, em que o personagem Alcimo acaba sendo enganado e derrubado da janela pela velha que protege as riquezas de seu quarto.

Ressaltamos ainda, em nossa tradução, o uso de adjetivos hiperbólicos e vocábulos cuja etimologia ressoava, para nós, bastante significativos no texto original. A respeito deste, seguimos o texto editado por Robertson (APULEE, 2007), da coleção Les Belles Lettres.

\section{APULEIO - As Metamorfoses 4.8-22}

[8] Commodum cubuerant et ecce quidam longe plures numero iuvenes adveniunt alii, quos incunctanter adaeque latrones arbitrarere. Nam et ipsi praedas aureorum argentariorumque nummorum ae vasculorum vestisque sericae et intextae filis aureis invehebant. Hi simili lavacro refoti inter toros sociorum sese reponunt, tunc sorte 
ducti ministerium faciunt. Estur ac potatur incondite, pulmentis acervatim, panibus aggeratim, poculis agminatim ingestis. Clamore ludunt, strepitu cantillant, conviciis iocantur, ac iam cetera semiferis Lapithis [tebcinibus $]^{2}$ Centaurisque $<$ semihominibus $>$ similia. Tunc inter eos unus, qui robore ceteros antistabat: 'Nos quidem' inquit '<qui> Milonis Hypatini domum fortiter expugnavimus, praeter tantam fortunae copiam, quam nostra virtute nacti sumus, et incolumi numero castra nostra petivimus et, si quid ad rem facit, octo pedibus auctiores remeavimus. At vos, qui Boeotias urbes appetistis, ipso duce vestro fortissimo Lamacho deminuti debilem numerum reduxistis, cuius salutem merito sarcinis istis quas advexistis omnibus antetulerim. Sed illum quidem utcumque nimia virtus sua peremit; inter inclitos reges ac duces proeliorum tanti viri memoria celebrabitur. Enim vos bonae frugi latrones inter furta parva atque servilia timidule per balneas et aniles cellulas reptantes scrutariam facitis.'

[9] Suscipit unus ex illo posteriore numero: 'Tune solus ignoras longe faciliores ad expugnandum domui esse maiores? Quippe quod, licet numerosa familia latis deversetur aedibus, tamen quisque magis suae saluti quam domini consulat opibus. Frugi autem et solitarii homines fortunam parvam vel certe satis amplam dissimulanter obtectam protegunt acrius et sanguinis sui periculo muniunt. Res ipsa denique fidem sermoni meo dabit. Vix enim Thebas heptapylos accessimus: quod est huic disciplinae primarum studium, [sed dum] sedulo fortunas inquirebamus popularium; nec nos denique latuit Chryseros quidam nummularius copiosae pecuniae dominus, qui metu officiorum ac munerum publicorum magnis artibus magnam dissimulabat opulentiam. Denique solus ac solitarius parva sed satis munita domuncula contentus, pannosus alioquin ac sordidus, aureos folles incubabat. Ergo placuit ad hunc primum ferremus aditum, ut contempta pugna manus unicae nullo negotio cunctis opibus otiose potiremur.

[10] Nec mora, cum noctis initio foribus eius praestolamur, quas neque sublevare neque dimovere ac ne perfringere quidem nobis videbatur, ne vulvarum sonus cunctam viciniam nostri suscitaret exitio. Tunc itaque sublimis ille vexillariis noster Lamachus spectatae virtutis suae fiducia, qua clavi immittendae foramen patebat, sensim inmissa manu claustrum evellere gestiebat. Sed dudum scilicet omnium bipedum nequissimus Chryseros vigilans et singula rerum sentiens lenem gradum et obnixum silentium tolerans paulatim adrepit, grandique clavo manum ducis nostri repente nisu fortissimo ad ostii tabulam officit et exitiabili nexu patibulatum relinquens gurgustioli sui tectum ascendit, atque inde contentissima voce clamitans rogansque vicinos et unum quemque proprio nomine ciens et salutis communis admonens diffamat incendio repentino domum suam possideri. Sic unus quisque proximi periculi confinio territus suppetiatum decurrunt anxii.

[11] Tunc nos in ancipiti periculo constituti vel opprimendi nostri vel deserendi socii remedium e re nata validum eo volente comminiscimus. Antesignani nostri partem, qua manus umerum subit, ictu per articulum medium temperato prorsus abscidimos, atque ibi brachio relicto, multis laciniis offulto vulnere ne stillae sanguinis vestigium proderent, ceterum Lamachum raptim reportamos. Ac dum trepidi religionis urguemur gravi tumultu et instantis periculi metu terremur ad fugam nec vel sequi propere vel remanere tuto potest vir sublimis animi virtutisque praecipuus, multis nos

\footnotetext{
${ }^{2}$ Essa passagem apresenta grandes dificuldades de leitura nos papiros e um grande número de propostas tem sido levantadas para resolver o significado de tebcinibus. Segundo Gaselee (Apuleius, 1958), Hensius propõe uma emenda para tebainibus. Helm (1931) sugere a palavra cenantibus, que, para Hijmans (1977), embora seja possível do ponto de vista paleográfico, apresenta um significado um pouco raso, por isso ele prefere a palavra tuburcinantibus, do verbo tuburcinor, comer sofregamente, que aparece em outras ocasiões em Apuleio.
} 
adfatibus multisque precibus querens adhortatur per dexteram Martis per fidem sacramenti bonum commilitonem cruciatu simul et captivitate liberaremos.

Cur enim manui, quae rapere et iugulare sola posset, fortem latronem supervivere? Sat se beatum qui manu socia volens occumberet. Cumque nulli nostrum spontale parricidium suadens persuadere posset, manu reliqua sumptum gladium suum diuque deosculatum per medium pectus ictu fortissimo transadigit. Tunc nos magnanimi ducis vigore venerato corpus reliquum veste lintea diligenter convolutum mari celandum commisimus. Et nunc iacet noster Lamachus elemento toto sepultus.

[12] Et ille quidem dignum virtutibus suis vitae terminum posuit. Enim vero Alcimus sollertibus coeptis eo saevum Fortunae nutum non potuit adducere. Qui cum dormientis anus perfracto tuguriolo conscendisset cubiculum superius iamque protinus oblisis faucibus interstinguere eam debuisset, prius maluit rerum singula per latiorem fenestram forinsecus nobis scilicet rapienda dispergere. Cumque iam cuncta rerum naviter emolitus nec toro quidem aniculae quiescentis parcere vellet eaque lectulo suo devoluta vestem stragulam subductam scilicet iactare similiter destinaret, genibus eius profusa sic nequissima illa deprecatur: 'Quid, oro, fili, paupertinas pannosasque resculas miserrimae anus donas vicinis divitibus, quorum haec fenestra domum prospicit?' Quo sermone callido deceptus astu et vera quae dicta sunt credens Alcimus, verens scilicet ne et ea quae prius miserat quaeque postea missurus foret non sociis suis sed in alienos lares iam certus erroris abiceret, suspendit se fenestra sagaciter perspecturus omnia, praesertim domus attiguae, quam dixerat illa, fortunas arbitraturus.

Quod eum strenue quidem sed satis improvide conantem senile illud facinus quamquam invalido repentino tamen et inopinato pulsu, nutantem ac pendulum et in prospectu alioquin attonitum praeceps inegit. Qui praeter altitudinem nimiam super quendam etiam vastissimum lapidem propter iacentem decidens perfracta diffissaque crate costarum rivos sanguinis vomens imitus narratisque nobis quae gesta sunt non diu cruciatus vitam evasit. Quem prioris exemplo sepulturae traditum bonum secutorem Lamacho dedimus.

[13] Tunc orbitatis duplici plaga petiti, iamque Thebanis conatibus abnuentes Plataeas proximam conscendimus civitatem. Ibi famam celebrem super quodam Demochare munus edituro gladiatorium deprehendimus. Nam vir et genere primarius et opibus plurimus et liberalitate praecipuus digno fortunae suae splendore publicas voluptates instruebat. Quis tantus ingenii, quis facundiae, qui singulas species apparatus multiiugi verbis idoneis posset explicare? Gladiatores isti famosae manus, venatores illi prolatae pernicitatis, alibi noxii perdita securitate suis epulis bestiarum saginas instruentes; confixilis machinae sublicae, turres structae tabularum nexibus ad instar circumforaneae domus, florida pictura decora futurae venationis receptacula. Qui praeterea numerus, quae facies ferarum! Nam praecipuo studio forinsecus etiam advexerat generosa illa damnatorum capitum funera. Sed praeter ceteram speciosi muneris supellectilem totis utcumque patrimonii viribus immanis ursae comparabat numerum copiosum. Nam praeter domesticis venationibus captas, praeter largis emptionibus partas, amicorum etiam donationibus variis certatim oblatas tutela sumptuosa solicite nutriebat.

[14] Nec ille tam clarus tamque splendidus publicae voluptatis apparatus invidiae noxios effugit oculos. Nam diutina captivitate fatigatae simul et aestiva flagrantia maceratae, pigra etiam sessione languidae, repentina correptae pestilentia paene ad nullum redivere numerum. Passim per plateas plurimas cerneres iacere semivivorum corporum ferina naufragia. Tunc vulgus ignobile, quos inculta pauperies sine delectu ciborum tenuato ventri cogit sordentia supplementa et dapes gratuitas conquirere, passim iacentes epulas accurrunt. Tunc e re nata subtile consilium ego et 
iste Eubulus tale comminiscimur. Vnam, quae ceteris sarcina corporis praevalebat, quasi cibo parandam portamus ad nostrum receptaculum, eiusque probe nudatum carnibus corium servatis sollerter totis unguibus, ipso etiam bestiae capite adusque confinium cervicis solido relicto, tergus omne rasura studiosa tenuamos et minuto cinere perspersum soli siccandum tradimus.

Ac dum caelestis vaporis flammis examurgatur, nos interdum pulpis eius valenter saginantes sic instanti militiae disponimus sacramentum, ut unus e numero nostro, non qui corporis adeo sed animi robore ceteris antistaret, atque is in primis voluntarius, pelle illa contectus ursae subiret effigiem domumque Democharis inlatus per opportuna noctis silentia nobis ianuae faciles praestaret aditus.

[15] Nec paucos fortissimi collegii sollers species ad munus obeundum adrexerat. Quorum prae ceteris Thrasyleon factionis optione delectus ancipitis machinae subivit aleam, iamque habili corio et mollitie tractabili vultu sereno sese recondit. Tunc tenui sarcimine summas oras eius adaequamus et iuncturae rimam, licet gracilem, saetae circumfluentis densitate saepimus. Ad ipsum confinium gulae, qua cervix bestiae fuerat exsecta, Thrasyleonis caput subire cogimus, parvisque respiratui <et obtutui $>$ circa nares et oculos datis foraminibus fortissimum socium nostrum prorsus bestiam factum inmittimus caveae modico praestinatae pretio, quam constanti vigore festinus irrepsit ipse. Ad hunc modum prioribus inchoatis $\mathrm{sic}<\mathrm{ad}>$ reliqua fallaciae pergimus.

[16] Sciscitati nomen cuiusdam Nicanoris, qui genere Thracio proditus ius amicitiae summum cum illo Demochare colebat, litteras adfingimus, ut venationis, suae primitias bonus amicus videretur ornando muneri dedicasse. Iamque provecta vespera abusi praesidio tenebrarum Thrasyleonis caveam Demochari cum litteris illis adulterinis offerimus, qui miratus bestiae magnitudinem suique contubernalis opportuna liberalitate laetatus iubet nobis protinus gaudii sui <ut ipse habebat $>$ gerulis decem aureos, [ut ipse habebat], e suis loculis adnumerari. Tunc, ut novitas consuevit ad repentinas visiones animos hominum pellicere, multi numero mirabundi bestiam confluebant, quorum satis callenter curiosos aspectus Thrasyleon noster impetu minaci frequenter inhibebat; consonaque civium voce satis felix ac beatus Demochares ille saepe celebratus, quod post tantam cladem ferarum novo proventu quoquo modo fortunae resisteret, iubet novalibus suis confestim bestiam [iret iubet] summa cum diligentia reportari. Sed suscipiens ego:

[17] 'Caveas,' inquam 'Domine, flagrantia solis et itineris spatio fatigatam coetui multarum et, ut audio, non recte valentium committere ferarum. Quin potius domus tuae patulum ac perflabilem locum immo et lacu aliquoi conterminum refrigerantemque prospicis? An ignoras hoc genus bestiae lucos consitos et specus roridos et fontes amoenos semper incubare?'

Talibus monitis Demochares perterritus numerumque perditarum secum recensens non difficulter adsensus ut ex arbitrio nostro caveam locaremus facile permisit. 'Sed et nos' inquam 'Ipsi parati sumus hic ibidem pro cavea ista excubare noctes, ut aestus et vexationis incommodo bestiae fatigatae et cibum tempestivum et potum solitum accuratius offeramus.'

'Nihil indigemus labore isto vestro;' respondit ille 'iam paene tota familia per diutinam consuetudinem nutriendis ursis exercitata est.'

[18] Post haec valefacto discessimus et portam civitatis egressi monumentum quoddam conspicamur procul a via remoto et abdito loco positum. Ibi capulos carie et vetustate semitectos, quis inhabitabant pulverei et iam cinerosi mortui, passim ad futurae praedae receptacula reseramus, et, ex disciplina sectae servato noctis inlunio tempore, quo somnus obvius impetu primo corda mortalium validius invadit ac premit, cohortem nostram gladiis armatam ante ipsas fores Democharis velut expilationis 
vadimonium sistimus. Nec setius Thrasyleon, examussim capto noctis latrocinali momento prorepit cavea statimque custodes, qui propter sopiti quiescebant, omnes ad unum mox etiam ianitorem ipsum gladio conficit, clavique subtracta fores ianuae repandit nobisque prompte convolantibus et domus alveo receptis demonstrat horreum, ubi vespera sagaciter argentum copiosum recondi viderat. Quo protinus perfracto confertae manus violentia, iubeo singulos commilitonum asportari quantum quisque poterat auri vel argenti et in illis aedibus fidelissimorum mortuorum occultare propere rursumque concito gradu recurrentes sarcinas iterare; quod enim ex usu foret omnium, me solum resistentem pro domus limine cuncta rerum exploraturum solicite, dum redirent. Nam et facies ursae mediis aedibus discurrentis ad proterrendos, si qui de familia forte evigilassent, videbatur opportuna. Quis enim, quamuis fortis et intrepidus, immani forma tantae bestiae noctu praesertim visitata non se ad fugam statim concitaret, non obdito cellae pessulo pavens et trepidus sese cohiberet?

[19] His omnibus salubri consilio recte dispositis occurrit scaevus eventos. Namque dum reduces socios nostros suspensus opperior, quidam servulus strepitu scilicet <uel certe> divinitus inquietus proserpit leniter visaque bestia, quae libere discurrens totis aedibus commeabat, premens obnixum silentium vestigium suum replicat et utcumque cunctis in domo visa pronuntiat. Nec mora, cum numerosae familiae frequentia domus tota completur. Taedis lucernis cereis, sebaciis et ceteris nocturni luminis instrumentis clarescunt tenebrae. Nec inermis quisquam de tanta copia processit, sed singuli fustibus lanceis destrictis denique gladiis armati muniunt aditus. Nec secus canes etiam venaticos auritos illos et horricomes ad comprimendam bestiam cohortantur.

[20] Tunc ego sensim gliscente adhuc illo tumultu retrogradi fuga domo facesso, sed plane Thrasyleonem mire canibus repugnantem latens pone ianuam ipse prospicio. Quamquam enim vitae metas ultimas obiret, non tamen sui nostrique vel pristinae virtutis oblitus iam faucibus ipsis hiantis Cerberi reluctabat. Scaenam denique quam sponte sumpserat cum anima retinens, nunc fugiens, nunc resistens variis corporis sui schemis ac motibus tandem domo prolapsus est. Nec tamen, quamvis publica potitus libertate, salutem fuga quaerere potuit. Quippe cuncti canes de proximo angiportu satis feri satisque copiosi venaticis illis, qui commodum domo similiter insequentes processerant, se obmiscent agminatim. Miserum funestumque spectamen aspexi, Thrasyleonem nostrum catervis canum saevientium cinctum atque obsessum multisque numero morsibus laniatum. Denique tanti doloris impatiens populi circumfluentis turbelis immisceor et, in quo solo poteram celatum auxilium bono ferre commilitoni, sic indaginis principes dehortabar: 'O grande' inquam 'Et extremum flagitium, magnam et vere pretiosam perdimus bestiam'.

[21] Nec tamen nostri sermonis artes infelicissimo profuerunt iuveni; quippe quidam procurrens e domo procerus et validus incunctanter lanceam mediis iniecit ursae praecordiis nec secus alius et ecce plurimi iam timore discusso, certatim gladios etiam de proximo congerunt. Enimvero Thrasyleon egregium decus nostrae factionis tandem immortalitate digno illo spiritu expugnato magis quam patientia neque clamore ac ne ululatu quidem fidem sacramenti prodidit, sed iam morsibus laceratus ferroque laniatus obnixo mugitu et ferino fremitu praesentem casum generoso vigore tolerans gloriam sibi reservavit, vitam fato reddidit. Tanto tamen terrore tantaque formidine coetum illum turbaverat, ut usque diluculum immo et in multum diem nemo quisquam fuerit ausus quamvis iacentem bestiam vel digito contigere, nisi tandem pigre ac timide quidam lanius paulo fidentior utero bestiae resecto ursae magnificum despoliavit latronem. Sic etiam Thrasyleon nobis perivit, sed a gloria non peribit. Confestim itaque constrictis sarcinis illis, quas nobis servaverant fideles mortui, Plataeae terminos concito gradu 
deserentes istud apud nostros animos identidem reputabamus merito nullam fidem in vita nostra reperiri, quod ad manis iam et mortuos odio perfidiae nostrae demigrarit. Sic onere vecturae simul et asperitate viae toti fatigati tribus comitum desideratis istas quas videtis praedas adveximus.

[22] Post istum sermonis terminum poculis aureis memoriae defunctorum commilitonum vino mero libant, dehinc canticis quibusdam Marti deo blanditi paululum conquiescunt.

\section{Tradução e Notas:}

[8] Naquela ocasião, estavam deitados, e eis que à certa distância outros jovens chegam em grande número, os quais sem hesitação tu igualmente julgarias como ladrões. Ora, também eles traziam despojos, moedas e vasinhos de ouro e prata, vestes de seda entrelaçadas com fios de ouro: refeitos em mesmo lavatório, eles se reclinam em leitos junto a seus companheiros, depois que, pela sorte, os escolhidos cumprem o seu serviço. Come-se e bebe-se a torto e a direito, iguarias aos montes, pães às fornadas e copos copiosamente entornados; com brados brincam, com estrépito cantam, com injúrias zombam, e em pouco tempo, eram símiles às comilanças de lápitas ${ }^{3}$, semiferas, e de centauros, semi-homens. Então um deles, que superava os outros em vigor, disse: "Nós, de fato, que assaltamos valentemente a casa de Milão de Hípata, sem falar da tão copiosa fortuna que pela virtude conseguimos, e com o número de soldados incólume voltamos para nossa fortaleza, e se isto contribui ao assunto, retornamos oito vezes mais ricos em pernas. Mas vós, que atacastes as cidades beócias, voltastes com uma tropa débil, tendo perdido o próprio líder, o valentíssimo Lâmaco ${ }^{4}$, cuja salvação me seria mais preciosa do que toda essa tranqueira que trouxestes. Mas, enfim, foi a demasiada coragem dele que o matou. Entre os egrégios reis e condutores de batalhas será celebrada a memória de tamanho varão. De fato, vós, bons e pobres ladrões, no meio de furtos pequenos e próprios de escravos, arrastando-se medrosamente nos banhos e nos quartinhos das velhas, vos tornastes mercadores de quinquilharias".

[9] Um daquele último bando respondeu: "Então, só tu ignoras que as casas maiores são, de longe, mais fáceis de serem assaltadas? Sem dúvida que, embora em casas espaçosas uma numerosa família ${ }^{5}$ seja hospedada, entretanto, cada um se ocupa antes com sua salvação do que com as riquezas do seu senhor. Ao passo que os homens pobres e solitários com fortuna parca ou, em poucos casos, bastante ampla, e mantida em segredo, a protegem mais duramente e a defendem arriscando o seu sangue. $\mathrm{O}$ próprio caso, enfim, exporá a veracidade do meu discurso: com efeito, tão logo chegamos a Tebas de Sete Portas ${ }^{6}$ - essa é a primeira tarefa dessa arte - inquirimos com zelo sobre as fortunas da população. E não nos foi ocultado que existia um certo

\footnotetext{
${ }^{3}$ Lápitas são um povo da Tessália, que intervém em diversas lendas da mitologia antiga. Em uma delas, ajudaram Teseu e Pirítoo a expulsar os centauros da Tessália. Pirítoo convidou os centauros para seu casamento com Hipodâmia, mas eles não estavam acostumados a beber e ficaram extremamente embriagados, ao ponto de um deles tentar violentar Hipodâmia, iniciando uma grande luta contra os lápitas, a qual terminará com a vitória destes.

${ }^{4}$ Lâmaco, "o que ama a guerra", é um nome formado pelo substantivo $\mu \alpha \chi \eta ́$ (maché), "guerra", e pelo prefixo $\lambda \alpha-(l a)$, que indica ênfase. O nome Lâmaco, além disso, remete ao general grego que morreu em Siracusa em 414 a.C., durante a expedição à Sicília na Guerra do Peloponeso.

${ }^{5}$ Segundo Grimal (1981, p.23), o conceito romano de família "[...] compreende não apenas o pai e a mãe, mas ainda os filhos casados e os criados", ou seja, todos aqueles que vivem sob uma mesma casa (domus) e, por isso, a casa romana era dividida em pequenos recintos em que cada um desses grupos habitava.

${ }^{6}$ Esse epíteto aparece em Homero, Il. IV, 406 e Od. XI, 263, retomando a lendária expedição dos Sete contra Tebas.
} 
Críseros $^{7}$, banqueiro dono de copiosa riqueza, que, por temor das obrigações e dos encargos públicos, dissimulava com grande habilidade a grande opulência. Em suma, só e solitário, contentando-se com uma casinha pobre, mas suficientemente munida e, além do mais, esfarrapado e sujo, deitava-se sobre sacos de ouro. Então, nos pareceu acertado que iniciássemos a abordagem por ele, pois seríamos possuidores, tranquilamente e sem nenhum esforço, de todos os seus bens. Desprezávamos, assim, a altivez de uma única mão.

[10] Sem demora, com o início da noite, aguardamos diante da sua porta, que não nos parecia bem nem derrubar, nem demover, nem arrombar, para que o som dos $\operatorname{lábios}^{8}$ da porta não acordasse toda vizinhança com a destruição. Sendo assim, aquele nosso Lâmaco, sublime entre os falsários, com o arrojo de sua já comprovada coragem, por onde se abria o buraco da chave cautelosamente enfiando a mão, ansiava por soltar o fecho. Porém, Críseros, sem dúvida, o mais velhaco de todos os bípedes, vigiando há algum tempo e percebendo cada um dos nossos comedidos passos, mantendo um absoluto silêncio, lentamente rastejou, e, de repente, com um grande cravo e um golpe fortíssimo, cravou $^{9}$ a mão do nosso chefe na tábua da porta. Deixando-o preso ao patíbulo para a morte, subiu no teto de sua bodeguinha e de lá, com voz contentíssima, clamando e rogando aos vizinhos, intimando cada um pelo próprio nome e exortando a salvação comum, inventa que sua casa foi tomada por um incêndio repentino. Deste modo, cada um dos vizinhos, horrorizado pela proximidade do perigo próximo, corre em auxílio do desesperado.

[11] Assim, tomados por um perigo duplo, ou de sermos esmagados ou de abandonarmos nossos companheiros, imaginamos uma solução vigorosa, nascida da circunstância e consentida pelo chefe. Cortamos do nosso líder a parte que liga a mão ao ombro, com um golpe calculado, direto e bem no meio da articulação. Tendo largado o braço ali, com a ferida tapada por muitos trapos, para que os vestígios de sangue não denunciassem nosso rastro, nós arrebatadamente carregamos o que restava de Lâmaco. Enquanto, assustados pelo escrúpulo, éramos impelidos em grande desordem e, instados pelo medo do perigo, com terror éramos postos em fuga, sem poder nem seguir depressa nem permanecer em segurança, o varão ${ }^{10}$ de excelsa alma e virtude distinta, queixandose com numerosas falas e numerosas súplicas, nos exorta, pela destra de Marte ${ }^{11}$ e pela fé ao juramento, que libertássemos um bom companheiro de armas, ao mesmo tempo, da dor e do cativeiro. Por que sem a mão quer sobreviver um ladrão forte, que só sabe rapinar e degolar? Mais feliz aquele que sucumbe voluntariamente pela mão de um companheiro. Em todo caso, não conseguia persuadir a nenhum de nós o espontâneo

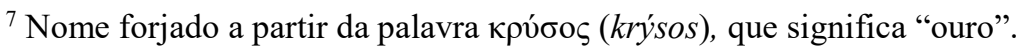

${ }^{8} \mathrm{O}$ termo utilizado por Apuleio é vulvarum, genitivo plural de vulva que, segundo Saraiva atesta (2006, p.1293, cf. vulva), significa "vulva ou ventre". Escolhemos a palavra "lábios" para manter a imagem metafórica, uma vez que tal palavra em português, além de designar o contorno da fenda bucal, refere-se também às bordas laterais da vagina.

${ }^{9}$ Buscamos com a repetição cravo/cravou criar o efeito da repetição gradum/grandique do texto latino.

${ }^{10}$ Lâmaco é caracterizado pela palavra uir, "varão", possuidor de uma virtude distinta. Conforme demonstra Rocha Pereira (1990, p. 400), virtutis, etimologicamente aparentada a uir, em sua acepção mais literal significa "ser homem direito". Segundo Rocha Pereira (1990, p.409), a evolução do conceito de virtutis é longa e repleta de nuances, mas que, de um modo geral, ele, de um sentido restrito de "valentia", "coragem" no campo bélico, vai ganhando noções mais abstratas referentes às qualidades de caráter, significado este que foi influenciado especialmente pela filosofia estoica. Pode-se dizer, entretanto, que a virtus tradicional "[...] consiste em alcançar fama e glória pelos seus feitos", ou seja, ressoa o conceito de ả $\rho \varepsilon \tau$ (areté) homérica, a excelência aristocrática e guerreira que, por meio das suas ações, pode alavancar o homem à fama imorredoura (PEREIRA, 1990, p.405).

${ }^{11}$ A referência a Marte, o deus da guerra, é paródica e busca dar um tom marcial ao suicídio de Lâmaco, já que o deus protetor dos ladrões era Mercúrio.
} 
parricídio que exortava, e, tendo agarrado com a mão restante sua espada e a beijado por muito tempo, transpassa com um golpe fortíssimo o imo peito ${ }^{12}$. Depois de venerarmos o vigor do chefe magnânimo, e tendo envolvido diligentemente o resto do corpo em uma veste de linho, o confiamos ao mar, que devia escondê-lo. E agora nosso Lâmaco jaz sepulto em um só elemento.

[12] Ele, de fato, deu à vida um fim digno de sua virtude. Com efeito, mesmo com seus engenhosos planos, Alcimo ${ }^{13}$ não pôde obter um temível sinal da Fortuna. Depois que arrombou o aposento de uma velha que dormia, ele subiu ao pavimento superior e, embora devesse matá-la imediatamente enforcando-a, preferiu primeiro arremessar cada uma de suas coisas a serem roubadas para fora da casa através de uma janela mais larga, para que nós, evidentemente, as agarrássemos. Em todo caso, tendo já removido todas as coisas diligentemente, não quis poupar nem mesmo o leito em que a velhinha repousava e, retirada, ela pôs-se lançar igualmente o estrado sem o lençol. Ela, derramada aos joelhos dele, pilantríssima assim fala: "Rogo, meu filho", disse ela, "por que doas essas coisinhas pobres e esfarrapadas de uma miserabilíssima velhinha para os vizinhos ricos, cuja casa essa janela dá de frente?’. Enganado pela lábia engenhosa e astuta e acreditando na veracidade do que ela dizia, e temendo, é claro, que também as coisas que arremessara primeiro, e as que ainda iria arremessar, não tivessem caído às mãos dos companheiros, mas nos lares vizinhos e já suspeitando do erro, Alcimo pendurou-se na janela para examinar tudo atentamente, mas, principalmente, para averiguar a tal fortuna da casa contígua, de que a velha falara.

Quando ele, corajosamente, é verdade, mas assaz imprudente, seguindo a pista da senil criminosa, embora de modo displicente, num impulso repentino e imediato, dependura-se e, penso na janela, atônito do que via, a velha o empurrou de cabeça. Caiu da grande altura sobre uma pedra grandíssima que ali havia; com as vértebras quebradas e rachadas, vomitava rios de sangue das entranhas - narrados para nós tais acontecimentos - e, não sofrendo por muito tempo, perdeu a vida. Como no caso precedente, oferecemos a ele a sepultura, entregando a Lâmaco um bom companheiro.

[13] Nesse momento, atingidos pela dúplice pancada da privação e rejeitando os esforços dos tebanos, para Plateia ${ }^{14}$, a cidade mais próxima, subimos. Aí, nessa cidade, ouvimos a célebre reputação de um espetáculo gladiatório a ser oferecido por um tal

\footnotetext{
$12 \mathrm{O}$ suicídio em Roma era visto como um ato nobre, defendido, por exemplo, pelos estoicos que o legitimavam em casos de devoção à pátria ou a familiares e amigos (OLIVEIRA, 1994, p. 67). Uma passagem da Farsália de Lucano é elucidativa para nos ajudar a ler a passagem do romance de Apuleio: o general Vulteio, vendo sua balsa cercada e sem meios de vencer a batalha, exorta seus soldados a se matarem, como prova de lealdade (fides) a César (Far. IV, 500-502), e, assim, conseguirem uma alta fama (Far. IV, 509). Os soldados cumprem a ordem de Vulteio.
}

\section{[...] Já de sangue}

repleta a balsa estava e o vencedor cremava os corpos: causou pasmo aos generais o quanto valia um general. Correu o mundo a Fama e nunca de uma balsa tanto ela falou

(Far., IV, 570-575, tradução de Brunno V. G. Vieira, (2011))

Percebe-se, nesta passagem, como o suicídio ganha ares de heroísmo, convertido em um ato que demonstra, além da coragem, a lealdade para com seus pares. Nesse sentido, Lâmaco demonstra uma grande virtude ao se matar, pois o faz para ajudar os seus camaradas de banditismo a fugirem. $\mathrm{O}$ termo fides que aparece vinculado ao juramento feito pelos bandidos denota o alto valor dado à palavra do ladrão que cumpre com os deveres estabelecidos por eles. Desse modo, a trajetória de Lâmaco ressoa vários elementos que configuram um típico herói épico.

${ }^{13}$ Nome forjado da palavra grega ő $\lambda \kappa \mu \nu \varsigma$ (álkimos), "corajoso", "forte", "robusto.

${ }^{14}$ Plateia é uma cidade beócia, ao sul de Tebas. 
Demócares ${ }^{15}$. De fato, o varão, não só excelente por sua origem e abundante pelas riquezas, mas também notável pela generosidade, promovia os prazeres do povo com o digno esplendor de sua fortuna. Quem cheio de talento, quem cheio de eloquência, que variegados recursos poderiam descrever, com hábeis palavras, as suas singulares maravilhas? Aqui, gladiadores de mão famosa, ali caçadores de agilidade comprovada, acolá uns ladrõezinhos que, tendo perdido a garantia de suas próprias refeições, serviam de refeição das feras; máquinas de dardos entrelaçados, torres de madeiras entrelaçadas à semelhança de tendas de ambulantes, decoradas com pintura florida e receptáculos para encenação de futuras caçadas. Além disso, que número e que aspecto das feras! De fato, com zelo notável, também importara publicamente aqueles magnificentes funerais dos condenados à morte.

Além de outras parafernálias do magnífico espetáculo, ele adquirira uma grande quantidade de enormes ursas com todos os recursos de seu patrimônio. Afora as feras capturadas em caçadas domésticas e as adquiridas em compras caras, também a sua suntuosa proteção nutria solicitamente aquelas continuamente provindas das muitas doações dos amigos.

[14] Mas aquele aparato para a satisfação do povo, tão grandioso quanto esplêndido, não escapou aos olhos nocivos da inveja. Com efeito, as feras, simultaneamente, fatigadas por um longo cativeiro, esgotadas pelo calor do acampamento e debilitadas pela duradoura inatividade, tendo contraído uma repentina peste, quase chegaram ao total aniquilamento. Por toda parte, via-se a enorme derrocada dos corpos semimortos das feras jazerem pelas praças de Plateia ${ }^{16}$. Então a multidão ignóbil - a quem a selvagem pobreza, sem que se escolham as comidas para atenuar o ventre, coage buscar os sórdidos suprimentos e as iguarias gratuitas - acorre às refeições que aqui e ali jaziam. Então, dessa situação surgida, nós, eu e Eubolo ${ }^{17}$, tramamos este meticuloso plano: transportamos uma ursa, que prevalecia entre as restantes pelo peso do corpo, para nosso esconderijo, como se fossemos preparar um jantar; o couro dela foi separado devidamente das carnes, todas as unhas foram habilmente preservadas e igualmente a própria cabeça da besta, até o limite do pescoço, foi mantida intacta. Todo o dorso, raspando com zelo, afinamos e, borrifando com cinzas trituradas em pó, a colocamos para secar. E, enquanto o dorso é secado pelos ardores do vapor celeste, nós, de tempos em tempos, alimentando-nos vigorosamente com essas carnes, planejamos, sob juramento militar, que um de nós, que fosse superior do resto não só no físico, mas ainda mais no vigor da alma, e em primeiro lugar que fosse voluntário, tendo se dissimulado com a pele da ursa, introduziria a efígie na casa de Demócares e, estando lá dentro, com o auxílio da oportuna calada da noite, daria acesso para nós facilmente pela porta.

[15] O hábil disfarce seduziu para empreender a tarefa não poucos do nosso fortíssimo grupo. Antes de todos, Trasileão ${ }^{18}$, tendo sido escolhido por opção da facção, expôs-se ao risco de nossa perigosa invenção, e, com o semblante sereno, já se ocultou

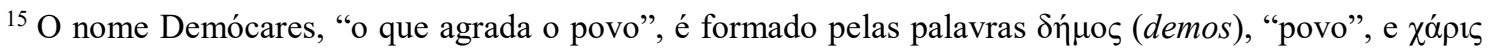
(cháris), "graça”, "prazer" ou "benefício".

${ }^{16}$ Apuleio, nessa passagem, brinca com a sonoridade das palavras parônimas platēa, "rua larga", "praça pública", e Platěa, nome da cidade grega. Diante da ausência de um vocábulo em português que fosse apropriado, tanto para transmitir o conteúdo, quanto para revelar esse jogo estilístico, preferimos usar a perífrase "praças de Plateia", em que a sonoridade pra/pla reforça a semelhança das palavras latinas.

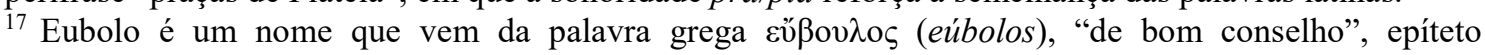
comumente usado para a deusa Témis, o que marca a ideia de que o plano sugerido pelo narrador e Eubolo é repleto de $\mu$ í $\iota \varsigma$ (métis), "inteligência", "astúcia" ou "sabedoria".

${ }^{18}$ O nome Trasileão, "o valoroso leão", é formado das palavras gregas $\theta \rho \alpha \sigma u ́ \varsigma$ (thrasýs), "corajoso", e

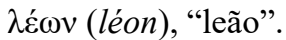


no couro convenientemente flexível e maleável. Depois disso, aplainamos as bordas superiores e a juntura das fendas com uma tênue costura, embora simples, e as cingimos densamente com o pelo abundante. Próximo ao próprio limite da garganta, onde fora cortado o pescoço da besta, forçamos a cabeça de Trasileão a entrar, e tendo sido feitos pequenos buracos em volta do nariz e dos olhos para a respiração e a visão, impelimos nosso valoroso companheiro, inteiramente transformado em besta, numa jaula comprada a preço módico, na qual ele próprio, adiantado, introduziu-se com inabalável vigor. Desse modo, após esses primeiros preparativos, continuamos com o restante do engodo.

[16] Informados de que um certo Nicanor ${ }^{19}$, de origem trácia, cultivava com aquele Demócares um elevado laço de amizade, bolamos uma carta, a fim de parecer que seu bom amigo tinha dedicado a ele a melhor parte de sua caçada brindando-o com um presente.

A tarde já ia avançada e, aproveitando a proteção das trevas, apresentamos a jaula de Trasileão para Demócares, junto com aquela carta forjada; ele, admirado com a magnitude da besta e regozijando-se com a oportuna generosidade do seu companheiro, imediatamente manda contar de sua bolsa dez moedas de ouro para nós, portadores, conforme julgava, de sua alegria. Então, como a novidade sempre costuma, diante das visões repentinas, seduzir os espíritos dos homens, acorria grande número de admiradores da besta, e aos olhares bastante perspicazes deles, o nosso Trasileão inibia frequentemente com ímpeto ameaçador; e junto à voz harmoniosa dos cidadãos, o feliz e opulento Demócares, tendo comemorado muito e muito - ele que, depois da enorme perda das feras, com a novidade resistia, de algum modo, ao seu destino - ordena de imediato que seja transportada a besta aos seus campos, com todo zelo do mundo. Mas eu intervim:

[17] "Cautela, senhor", eu disse, "para não colocar o animal, que está fatigado pelo calor do sol e pela longa viagem, em companhia de outros que, pelo que eu ouvi dizer, não estão com boa saúde. Por que antes não procura um lugar aberto e arejado dentro da sua casa, de preferência próximo ao refrigério de um espelho d'água? Acaso ignora que esta espécie de animal sempre tem por habitat bosques arborizados, cavernas úmidas e fontes amenas?"

Apavorado com semelhantes conselhos e revendo as suas numerosas perdas, Demócares, não dificilmente persuadido, permitiu de boa vontade que colocássemos o claustro conforme o nosso querer. "Mas", acrescentei, "nós mesmos estamos dispostos a montar guarda, à noite, aqui mesmo diante deste claustro, para oferecermos, com mais diligência, o alimento na hora certa e a bebida de costume para essa besta fatigada pelo incômodo do calor e da viagem".

"Não carecemos do seu trabalho", respondeu-me, "quase toda a família está habituada a dar de comer aos ursos, por constante prática".

[18] Depois disso, nos despedimos e nos retiramos e, tendo saído pela porta da cidade, avistamos um certo monumento ${ }^{20}$, afastado da estrada e situado em lugar remoto. Ali, abríamos, para serem esconderijos de nosso futuro roubo, os túmulos semicobertos de entulho e velharia, nos quais mortos, cobertos de cinza e pó, habitavam, e, de acordo com a doutrina de nossa seita, aguardamos a hora da noite da esconsa lua, em que o doce sono, com o primeiro ataque, com mais vigor invade e abate

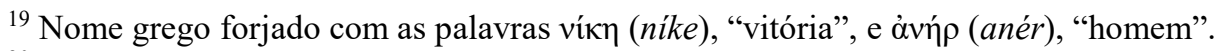

${ }^{20}$ Embora o termo "monumento" em português tenha uma acepção que remeta a construções grandiosas, preferimos utilizar este vernáculo para traduzir a palavra latina monumentum, por questões de etimologia. No entanto, o leitor deve levar em conta que a palavra latina refere-se especialmente a um "monumento funerário", sem a necessidade de um adjunto que a especifique, como sepulchri (SARAIVA, 2006, p. 751, cf. monumentum).
} 
os corações dos mortais; então alocamos a nossa legião, armada de gládios, diante da porta de Demócares com a promessa de pilhagem. Trasileão, atento ao momento exato do latrocínio noturno, saiu da jaula e de imediato matou, um a um com seu gládio, os guardas que repousavam adormecidos ali perto. Em seguida, também matou o porteiro e, tendo subtraído a chave, escancarou as portas da entrada. Uma vez que, prontamente, estávamos nos infiltrando e chegando no coração da casa, nos mostrou um depósito onde, à tarde, vira sagazmente uma copiosa quantidade de prata ser guardada. Imediatamente, com a dura violência das mãos, arrombamos essa dispensa e ordeno a cada um dos companheiros que carregue tudo quanto consiga de ouro e prata e rapidamente esconda nas casas dos mortos, os hiperconfiáveis, e, com pés velozes, volte correndo e recomece novamente os saques. Com efeito, eu sozinho, para o benefício de todos, me manteria diante do limiar da casa para observar cuidadosamente tudo que se passava enquanto eles iam e vinham. Pois, se alguém da família por acaso despertasse, seria vista a imagem oportuna de uma ursa correndo pela casa que os levaria ao terror.

Quem, de fato, por mais forte e intrépido, tendo visto, sobretudo à noite, uma fera com esse tamanho monstruoso, não se apressaria em fugir imediatamente e não se encerraria, tremendo e agitado, no quarto com um ferrolho para trancar?

[19] Tendo sido tomadas corretamente essas disposições salutares, ocorreu então um evento sinistro: pois, enquanto eu esperava inquieto os meus companheiros retornarem, um escravo, despertado certamente pelo tumulto, ou por vontade divina, se esgueirou de mansinho e avistou a besta, que circulava correndo livre por toda casa. Ele, mantendo um absoluto silêncio, dá meia volta e de um jeito qualquer anuncia a todos o que vira na casa. Sem demora, toda casa se encheu com a presença dos numerosos moradores: tochas, lâmpadas, círios, velas e vários outros instrumentos que iluminam a noite chamejaram as trevas; e ninguém, da enorme multidão, avançava inerme, mas cada um armado com achas, lanças, enfim, espadas desembainhadas, fortificava a entrada; além disso, atiçavam os cães de caça, esses cães orelhudos e hirsutos, para conter a besta. [20] Então, eu, com aquele tumulto crescendo lentamente mais e mais, bati em retirada da casa, mas, escondido atrás da porta, eu mesmo vi Trasileão lutar admiravelmente com os cães. Ainda que, com efeito, percorresse os últimos minutos de sua vida, não se esquecia nem de si, nem de nós, nem da antiga virtude, e por isso resistia às mordidas do Cérbero, que estava prestes a abocanhá-lo. Enfim, conservando com ânimo o papel que se arrogara por vontade própria, ora correndo, ora lutando, variando as formas e os movimentos do corpo, por fim fugiu da casa. Todavia, embora tenha se apoderado da liberdade da rua, não pôde encontrar a salvação da fuga, pois todos os cães do beco vizinho, bastante selvagens e numerosos, se misturaram em bando àqueles de caça, que precisamente acabavam de lançar-se da casa em sua perseguição. Que mísero e funesto espetáculo eu vi: o nosso Trasileão cercado e atacado por catervas de cães furiosos e dilacerado por muitas e numerosas mordidas.

Então, assomado por tanta dor, misturei-me ao tumulto do povo que me circundava, pois somente com isso eu poderia obter para o bom amigo uma furtiva ajuda, e desse modo distraía os principais caçadores do cerco: "Que vergonha", eu disse, "imensa e extrema, perdemos uma besta magnânima e verdadeiramente preciosa". [21] Contudo, minhas habilidades oratórias não foram úteis ao infelicíssimo jovem, pois, um certo homem, alto e robusto, saindo da casa, sem hesitar transpassou a lança no imo peito da ursa, e assim fez toda a multidão que, já com o medo dissuadido, energicamente o crivou com seus gládios imediatamente depois. Com efeito, Trasileão, insigne glória de nossa facção, finalmente subjugado aquele espírito digno de imortalidade mais do que de servidão, por certo não traiu a palavra dada em juramento nem com grito nem com gemido, mas, já lacerado pelas mordidas e rasgado pelo ferro, 
continuava mugindo e relinchando como uma fera, tolerando a presente situação com altivo vigor, conservando assim a sua glória, entregou a vida ao destino. Sem dúvida, ele perturbou aquele bando com um grande terror e com grande medo, até ao raiar do dia, ou melhor, até o dia claro, ninguém teve a audácia de encostar nem mesmo um dedo embora a besta estivesse no chão. Enfim, com lentidão e timidez, um carniceiro, um pouco mais ousado, depois de cortar a barriga da besta, tirou da ursa o magnífico ladrão. Assim, então, nosso Trasileão pereceu, mas a sua glória não terá fim. Imediatamente, por consequência, juntamos aqueles pacotes que os honestos mortos guardaram para nós, e deixando com passo apressado os limites de Plateia, repensávamos isto continuamente em nossas almas: que, em nossa vida, nenhuma boa fé é obtida pelo merecimento; e que, cansada de nossas perfídias, ela foi morar junto aos manes e aos mortos. Foi assim que todos fatigados pelo peso da carga e pela dureza da estrada, com três dos companheiros mortos, trouxemos os saques que vedes".

[22] Depois do término da narrativa, com copos de ouro fazem uma libação com vinho puro em memória dos companheiros defuntos; em seguida, tendo honrado o deus Marte com alguns cânticos, repousam um pouco.

\section{REFERÊNCIAS}

ADKINS, E. W. Rudis Locutor: Speech and Self-Fashioning in Apuleius' Metamorphoses. A dissertation submitted in partial fulfillment of the requirements for the degree of Doctor of Philosophy (Classical Studies) in the University of Michigan, 2014.

APULEE. Les métamorphoses. Texte établi par D. S. Robertson et traduit par Olivier Sers. Paris: Les Belles Lettres, 2007.

APULEIO. O asno de ouro. Tradução de Ruth Guimarães. São Paulo: Cultrix, 1963.

APULEIUS. The Golden Ass. Being the Metamorphoses of Lucius Apuleius. Translation by W. Adlington and revised by S. Gaselee. Cambridge; London: Harward University Press; William Heinemann, 1958.

BAKHTIN, M. Problemas da poética de Dostoiévski. Tradução de Paulo Bezerra. Rio de Janeiro: Forense-Universitária, 1981.

BRANDÃO, J. L. A invenção do romance. Brasília: Ed. UNB, 2005.

GRIMAL, P. A vida em Roma na Antiguidade. Tradução de Victor Jabouille, João Daniel Lourenço e Maria Cristina Pimentel. Sintra: Publicações Europa-América, 1981.

HARRISON, S. J. Apuleius and Homer: Some Traces of the Iliad in the Metamorphoses. In: PASCHALIS, M; PANAYOTAKIS, S; SCHMELING, G (Ed). Readers and Writers in the Ancient Novel. Groningen: Barkhuis Publishing and Groningen University Library, 2003. p.169-183.

HELM, R. (ed.). Apulei opera quae supersunt vol. 1: Metamorphoseon Libri XI. Leipzig: B.G. Teubner, 1931. 
HIJMANS, B. L., Jr., et al. Apuleius Madaurensis Metamorphoses Book IV.1-27. Groningen Commentaries on Apuleius. Groningen: Bouma, 1977

LUCANO. Farsália. Cantos de I a V. Tradução de Brunno V. G. Vieira. Campinas: Editora da Unicamp, 2011.

ODIL, J. de O. F. Carnaval no Convento. Intertextualidade e paródia em José Saramago. São Paulo: Editora Unesp, 1993.

OLIVEIRA, F. O suicídio na Roma Antiga. Máthesis, nº 3, p. 65-93, 1994.

PEREIRA, M. H. da R. Estudos de história da cultura clássica. Cultura Romana. Lisboa: Fundação Calouste Gulbenkian, 1990.

SARAIVA, F. R. dos S. Novíssimo dicionário Latino-Português. Rio de Janeiro; Belo Horizonte: Livraria Garnier, 2006.

Data de envio: 24-09-2017

Data de aprovação: 10-11-2017

Data de publicação: 22-12-2017 